\title{
Applications of the VARGOW Oil Reservoir Model
}

D. W. Mayer

December 1980

Prepared for the

U.S. Geological Survey

under a Related Services Agreement

with the U.S. Department of Energy

under Contract DE-AC06-76RLO 1830

Pacific Northwest Laboratory

Operated for the U.S. Department of Energy

by Battelle Memorial Institute 


\title{
NOTICE
}

This report was prepared as an account of work sponsored by the United States Government. Neither the United States nor the Department of Energy, nor any of their employees, nor any of their contractors, subcontractors, or their employees, makes any warranty, express or implied, or assumes any legal liability or responsibility for the accuracy. completeness or usefulness of any information, apparatus, product or process disclosed, or represents that its use would not infringe privately owned rights.

The views, opinions and conclusions contained in this report are those of the contractor and do not necessarily represent those of the United States Government or the United States Department of Energy.

\author{
PACIFIC NORTHWEST LABORATORY \\ operated by \\ BATTELLE \\ for the \\ UNITED STATES DEPARTMENT OF ENERGY \\ Under Contract DE-AC06-76RLO 1830
}

\author{
Printed in the United States of America \\ Available from \\ National Technical Information Service \\ United States Department of Commerce \\ 5285 Port Royal Road \\ Springfield, Virginia 22151
}

Price: Printed Copy $\mathbf{S}$

$\because$ Microfiche $\$ 3.00$

NTIS

•Pages Selling Price

$\begin{array}{ll}001-025 & \$ 4.00 \\ 026-050 & \$ 4.50 \\ 051-075 & \$ 5.25 \\ 076-100 & \$ 6.00 \\ 101-125 & \$ 6.50 \\ 126-150 & \$ 7.25 \\ 151-175 & \$ 8.00 \\ 176-200 & \$ 9.00 \\ 201-225 & \$ 9.25 \\ 226-250 & \$ 9.50 \\ 251-275 & \$ 10.75 \\ 276-300 & \$ 11.00\end{array}$




\section{6}

APPLICATIONS OF THE VARGOW

OIL RESERVOIR MODEL

D. W. Mayer

December 1980

Prepared for

the U.S. Geological Survey under a Related Service Agreement with the U.S. Department of Energy Contract DE-ACO6-76-RLO 1830

Pacific Northwest Laboratory

Operated for the U.S. Department of Energy by Battelle Memorial Institute 

This report is a continuation of work performed previously (Mayer et al. 1980) and serves as an addendum to the previous report. The purpose of this study is to perform additional simulations of three reservoirs using the VARGOW model. VARGOW is a variable gas-oil-water reservoir model that was developed by the U.S. Geological Survey to provide recovery estimates suitable for assessing various reservoir production policies and regulations.

One of the reservoirs was resimulated using better initial condition data. The other reservoirs were simulated using a modified gas segregation model. The major conclusions drawn from the study are that the VARGOW model can usually predict the reservoir pressure adequately but the producing gas/ oil ratio is not as successfully simulated. 
CONTENTS

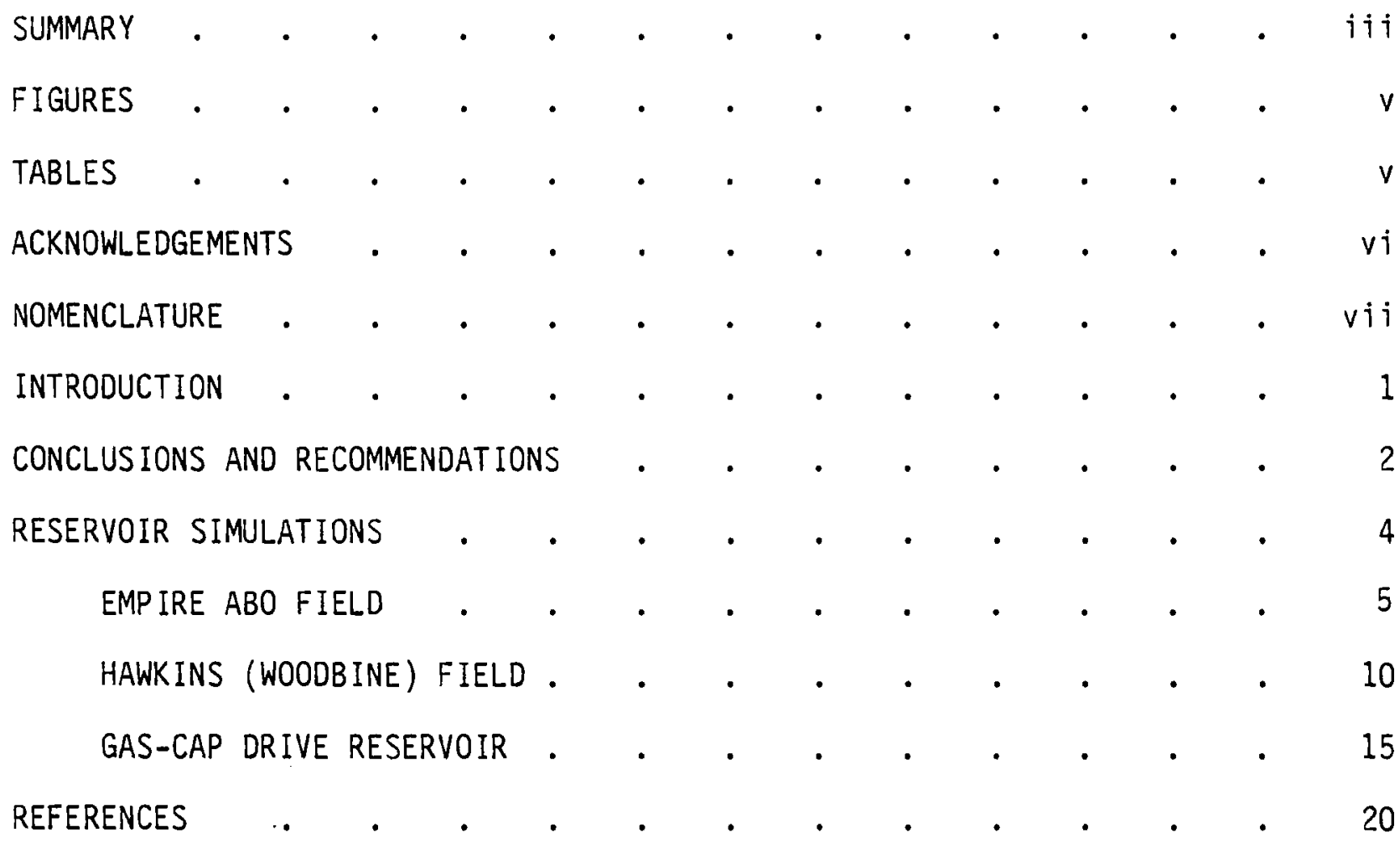




\section{FIGURES}

1 Empire Abo Pool Sixth Order Polynomial Pressure Curve . . . 7

2 Empire Abo Pool Second Order Polynomial GOR Curve . . . . 8

3 Empire Abo Pool Predicted Versus Actual Pressures . . . . 9

4 Empire Abo Pool Predicted Versus Actual GORs . . . . . . 11

5 Hawkins Field Predicted Versus Actual Pressures . . . . 14

6 Hawkins Field Predicted Versus Actual GORs . . . . . . . 16

7 Gas-Cap Reservoir Predicted Versus Actual Pressures . . . 17

8 Gas-Cap Reservoir Predicted Versus Actual GORs . . . . 19

\section{TABLES}

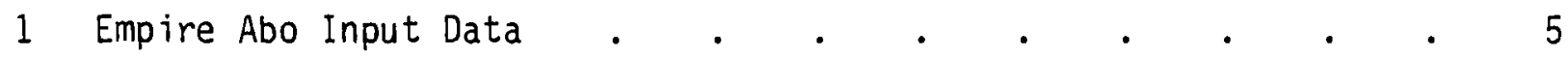

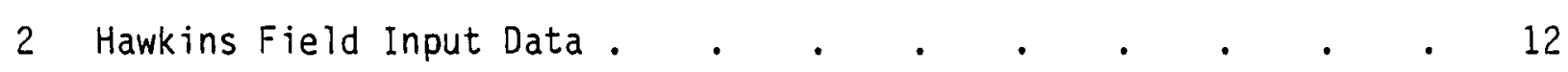

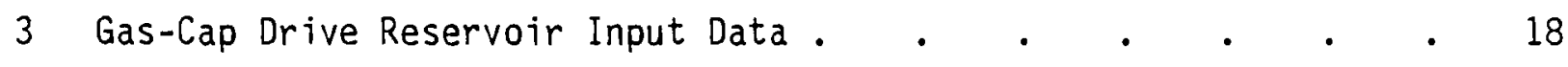




\section{ACKNOWLEDGMENTS}

Two PNL staff members provided valuable assistance throughout the execution of this project. Dr. Edward M. Arnold, serving as project manager, provided helpful review and comments on this report and valuable guidance during the study. Dr. W. M. Bowen performed the very essential statistical parameter estimation portion of the research program. 


\section{NOMENCLATURE}

A Intercept of the relative permeability ratio function

$B$ Slope of the relative permeability ratio function

C Schilthuis water drive constant, $\mathrm{ft}^{3} /$ year/psia

D Segregation damping factor, years

F $0 i 1 /$ gas entrapment factor (entrapment by the invading water)

$G \quad$ Initial gas/oil ratio, lb-moles gas/lb-mole oil

$\bar{G} \quad$ Average absolute GOR discrepancy, lb-mole/lb-mole

$K_{R} \quad$ Relative permeability ratio, $K_{R}=10^{(A+B \sigma)}$

$N$ Amount of a substance, lb-moles

$P$ Pressure, psia

$\bar{p} \quad$ Average absolute pressure discrepancy, psi

$r$ Rate of production, 1b-moles/year

$S$ Gas segregation factor

$\mathrm{T}$ Reservoir temperature, ${ }^{\circ} \mathrm{K}$

$v_{r} \quad 0 i l$ formation volume factor, RVB/STB

$v^{r}$ volume, $\mathrm{ft}^{3}$

$\gamma \quad$ Specific gravity

$\Theta \quad$ Time, years

$\sigma \quad$ Gas saturation, $\sigma=V_{F G} /\left(V_{F G}+V_{L}\right)$

$\Delta \quad$ Time constant in production model, 1/year

\section{SUBSCRIPTS}

$D G \quad$ Referring to dissolved gas

$F G \quad$ Referring to free gas

FG/PROD Referring to free gas produced from the reservoir

FGC Referring to free gas plus gas-cap gas

L Referring to reservoir liquid (oil plus dissolved gas)

L/PROD Referring to reservoir liquid produced from the reservoir

OIL Referring to oil

$R \quad$ Relative value

\section{SUPERSCRIPTS}

o Referring to time equal to zero. An initial condition.

- Indicates partial derivative with respect to time. 
APPLICATIONS OF THE VARGOW OIL RESERVOIR MODEL

D. W. Mayer

INTRODUCTION

The results discussed in the following report were obtained with a variable gas-oil-water (VARGOW) reservoir per se model developed by the U.S. Geological Survey (USGS 1976). The term "reservoir per se" indicates that the model considers only the reservoir itself and does not consider individual wells drilled into the reservoir. The only influence that wells have on the reservoir is in determining the rate of production.

The VARGOW model is a zero-dimensional tank-piston model. "Zerodimensional" indicates that spatial variations are not considered. "Tankpiston" implies that the reservoir is modeled as a large tank with the inflowing aquifer water forming a piston that pressurizes the reservoir. The "piston" is modeled as a porous piston that allows entrapment of the reservoir material (oil and gas) by the inflowing water.

The purpose of this report is to discuss the results obtained with the VARGOW model when applied to the following reservoirs:

- Empire Abo Pool, New Mexico

- Hawkins (Woodbine) Field, Texas

- A gas-cap drive reservoir, probably in Texas (exact location is unknown).

A similiar study has been conducted previously (Mayer et al. 1980). The present study is a continuation of that work. This report is therefore written as an addendum to the previous report and as such will not go into as many details of the modeling approach. 


\section{CONCLUSIONS AND RECOMMENDATIONS}

A number of conclusions can be drawn from the results presented in this report. Briefly, it can be concluded that:

- It is not always possible to obtain a single set of parameter values that will result in the best predicted pressures and the best predicted gas/oil ratios (GOR).

- The VARGOW model can interpolate historical pressure data that is quantitatively close to the observed values. Qualitatively the shape of the predicted pressure curve usually looks like the observed data al though in some cases it does not.

- Pressures can be predicted 2 or 3 years beyond the parameter estimation period. Longer extrapolations were not accurate in the cases examined.

- It is not always possible to get predicted producing GOR values that quantitatively or qualitatively match the observed GOR data. (This may be the reason that the first conclusion is drawn.)

Based on these conclusions it is recommended that certain parts of the VARGOW model be re-examined. Since it is more difficult to get accurate predictions of the producing GOR, the parts of the model that influence this value should be examined first. In particular, the flowing production equation (Equation 15 in USGS 1976) and the gas-segregation sub-model (Equations 29 and 30 in USGS 1976) should be re-evaluated.

The flowing free gas and reservoir liquid production relationship is given by:

$$
\frac{\dot{N}_{F G / P R O D}}{\dot{N}_{L / P R O D}}=K_{R} \frac{V_{L} / N_{L}}{V_{F G} / N_{F G}}
$$


A preliminary analysis of this equation indicates that the influence of the gas and liquid viscosity should be accounted for. To do this the right side of Equation (1) should be multiplied by the liquid/free-gas viscosity ratio, $\mu_{L} / \mu_{F G}$.

The model also assumes that $K_{R}$ can be approximated by a straight line on a semi-log plot of $K_{R}$ versus $\sigma$, the free gas saturation. This approximation is reasonable over a certain range of values for $\sigma$. Near the start of the simulation however, $\sigma$ is nearly zero. For these low values of $\sigma$ the value calculated for $K_{R}$ may be in error.

The gas segregation sub-model is given by:

$$
\frac{N_{G C}}{N_{F G}}=\frac{S_{E}}{1-S_{E}}
$$

where

$$
S_{E}=S e^{-D / \theta}
$$

Although this sub-model describes intuitively the migration of the gas vapor from the oil zone to the gas cap it is not based on the physics of the gas migration. It simply forces part of the gas vapor that is evolved to be in the gas cap. It is felt that a relationship based on the permeability of the reservoir media and a pressure gradient due to buoyancy or density variation may provide a more physically based description (at the expense of additional complexity). 


\section{RESERVOIR SIMULATIONS}

The three reservoirs simulated during this study were investigated in a previous report (Mayer et al. 1980). The approach taken in this study is essentially the same and the reader is therefore referred to the previous report for details of the simulation and parameter estimation procedure. The places where the present investigation has deviated notably from the previous study are discussed in the text at the appropriate points.

The reservoirs simulated are:

- Empire Abo field, New Mexico

- Hawkins (Woodbine) Field, Texas

- A gas-cap drive reservoir, probably in Texas.

The simulation procedure requires the specification of as many of the model input parameters as possible based on the published reservoir data. The remaining parameters are statistically estimated by minimizing $\bar{P}$ and $\bar{G}$ the average absolute pressure and GOR discrepancies over a given period of historical data. The discrepancy measures $\bar{P}$ and $\bar{G}$ are given by:

$$
\begin{aligned}
& \bar{P}=\sqrt{\sum_{t=1}^{n}\left(O P_{t}-P_{t}\right)^{2} / n} \\
& \bar{G}=\sqrt{\sum_{t=1}^{n}\left(O G_{t}-G_{t}\right)^{2} / n}
\end{aligned}
$$

The index $t$ ranges over $n$ specified times, and $O P_{t}=$ observed pressure at time $t$

$P_{t}=$ predicted pressure at time $t$

$O G_{t}=$ observed $G O R$ at time $t$

$G_{t}=$ predicted $G O R$ at time $t$. 
The Empire Abo Pool, located in southeastern New Mexico, has been simulated using the data in Table 1 . This data is based on information obtained from the papers by Killough and Foster (1979); Christianson (1977); and from the Annual Reports published by the New Mexico $0 i 1$ and Gas Engineering Committee (1958-1978). These values are different than the values used in the original report (Mayer et al. 1980, p. 16). The reason for this is that the present simulation was started at the time when the reservoir reached the bubble point pressure of the reservoir fluid. Starting at the bubble point pressure meets the model assumptions better.

TABLE 1. Empire Abo Input Data

\begin{tabular}{|c|c|}
\hline Parameter & Value \\
\hline A & -2.849 \\
\hline B & 6.275 \\
\hline c & est. (a) \\
\hline D & est. \\
\hline $\mathrm{F}$ & est. \\
\hline G & 1.3716 \\
\hline$N_{L}^{0}$ & $1.878490 \cdot 10^{9}$ \\
\hline$p^{0}$ & 2231 \\
\hline$r_{0 I L}^{0}$ & $N A(b)$ \\
\hline s & est. \\
\hline$T^{0}$ & 315.94 \\
\hline$V_{L}^{0}$ & $3.219795 \cdot 10^{9}$ \\
\hline$v_{r}$ & 1.5 \\
\hline$\Delta_{O I L} \mid$ & Actual Production \\
\hline MODEL $\}$ & Data Used \\
\hline
\end{tabular}

(a) These values estimated statistically

(b) Not applicable 
To determine when the reservoir pressure reached the bubble point it was necessary to perform a polynomial regression analysis on the observed pressure data. The resulting best-fit curve is a sixth order polynomial, shown in Figure 1. The solution to this polynomial equation with the pressure equal to the bubble-point pressure indicates that the reservoir reached the bubblepoint in mid-December 1959. Therefore, the simulation has been started on January 1, 1960.

A second polynomial regression analys is was performed on the observed GOR data. This analysis resulted in the second order polynomial shown in Figure 2. At the time corresponding to January 1, 1960 the GOR, based on the polynomial, is 1.3716 .

It was also necessary to adjust the amount of liquid in the reservoir, $N_{L}^{0}$ and the volume of the reservoir liquid, $V_{L}^{0}$ to account for the oil and gas production that occurred during the preceding two years. When this combination of parameters (with $v_{r}=1.606$ as in the previous study) was used in the model, the initial gas derivative (free gas plus gas-cap gas) $\dot{N}_{F G C}^{0}$ was negative. This is a physically unrealistic result and it was therefore necessary to adjust $v_{r}$ to 1.5 to achieve a positive value for $\dot{N}_{F G C}^{0}$. The resulting set of parameter values, see Table 1 , have been used during the parameter estimation phase of the study.

Estimating the remaining parameters, $C, D, F$, and $S$ required running the VARGOW model for 79 different combinations of the four parameters. The sevenyears of observed pressure and GOR data between January 1, 1960 and January 1, 1967 were used to estimate the parameters. This time span is denoted by the words "HISTORY MATCH" on Figure 3 and subsequent figures. The results of the parameter estimation indicate that for the following range of values:

$$
\begin{aligned}
40,000 & \leq C \leq 55,000 \\
6 & \leq D \leq 18 \\
1 & \leq F \leq 1.8 \\
S & =0.75
\end{aligned}
$$

Both the GOR and pressure discrepancies are minimized. The pressure discrepancy varies between $27 \mathrm{psi}$ and $29 \mathrm{psi}$ while the GOR discrepancy varies between 0.45 and 0.437 for this range of parameter values. 
2500.

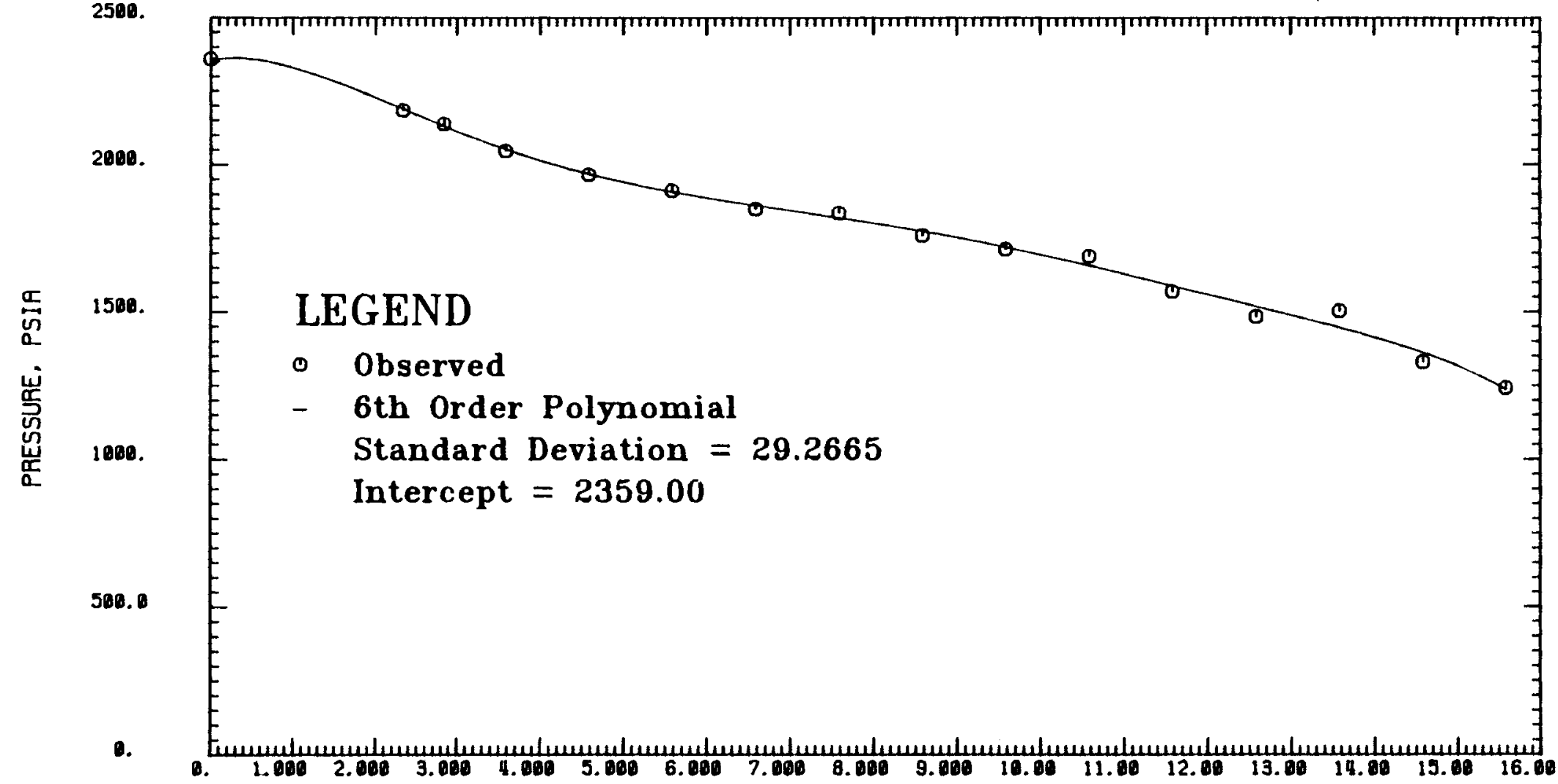

TIME, YEARS $(0 .=$ JANUARY 1,1958 )

FIGURE 1. Empire Abo Pool Sixth Order Polynomial Pressure Curve 


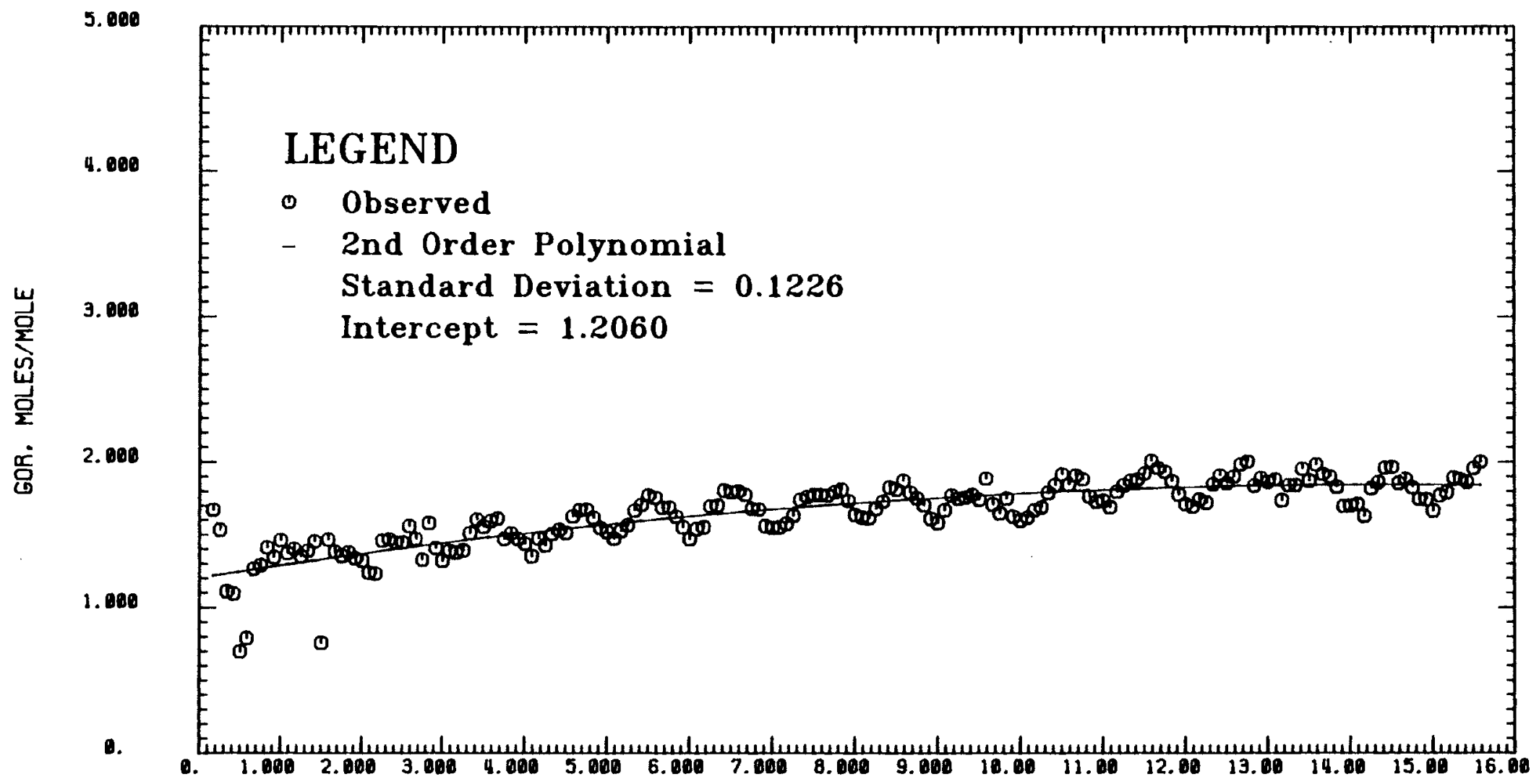

TIME, YEARS ( $0 .=$ JANUARY 1,1958 ]

FIGURE 2. Empire Abo Pool Second Order Polynomial GOR Curve 


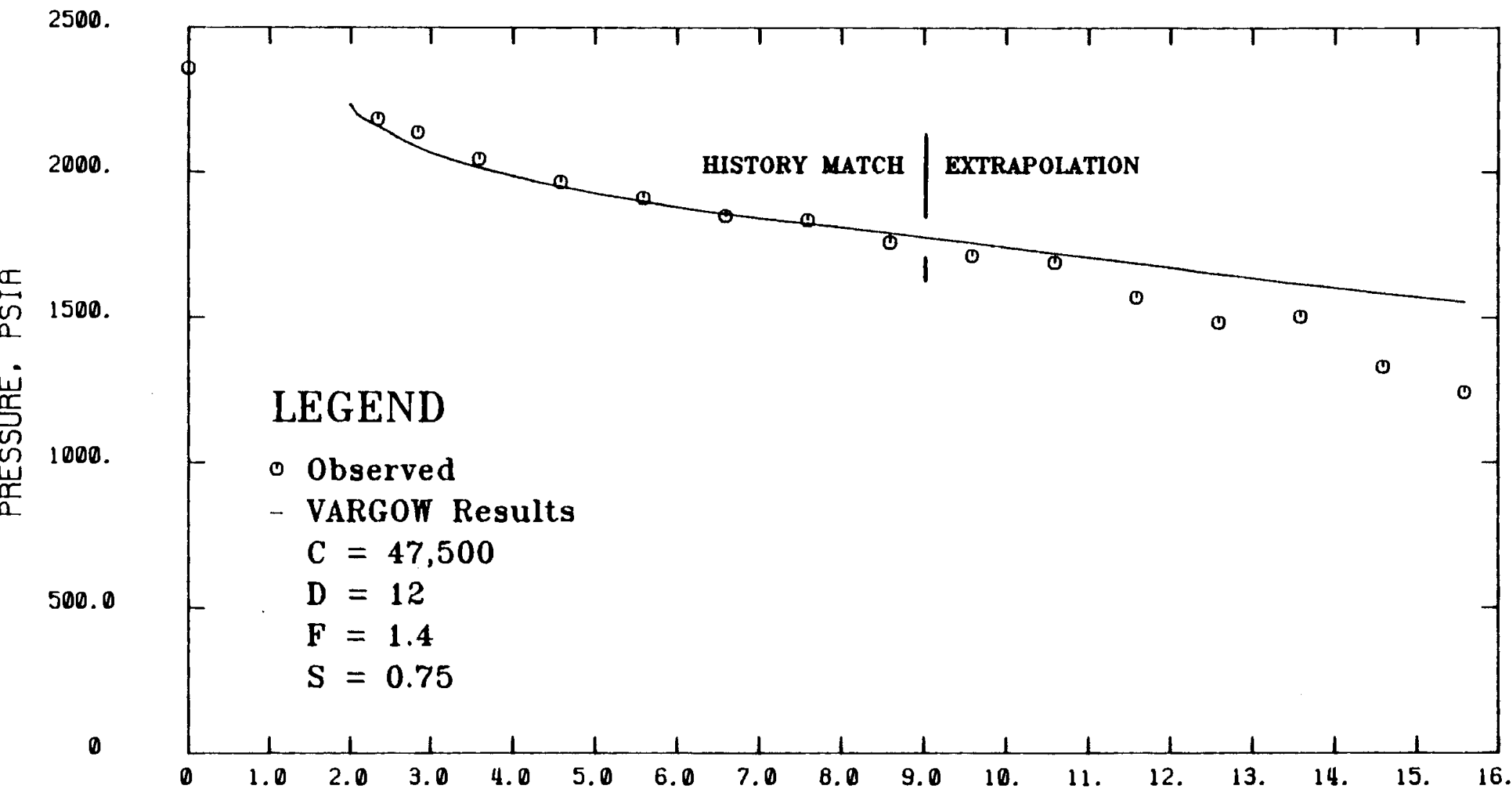

TIME, YERRS (0. = JANUARY 1,1958 ]

FIGURE 3. Empire Abo Pool Predicted Versus Actual Pressures 
Figures 3 and 4 are plots of the VARGOW results when the model is run with the four parameters at the midpoint of the value ranges. The pressure discrepancy for this combination is $27.45 \mathrm{ps} i$ and the GOR discrepancy is 0.4413 .

The model is able to predict the pressure quite well during the history match portion of the curve. In the extrapolation region (the time beyond the history match portion where the observed data has not been used to estimate the parameters) the model results start to deviate noticeably after about 2.5 years. The GOR data is not predicted well. At the end of the history match the predicted GOR is roughly $33 \%$ below the observed value and at the end of the extrapolation time the predicted value is nearly $50 \%$ of the observed value. Furthermore, the curvature of the predicted GORs is opposite the observed data. In general, the predicted values decrease and then start to level out with time while the observed values increase and then start to level out.

These results indicate that the portions of the model that influence gas production should be investigated. Starting points for this investigation could be the gas segregation formulations and the permeability equation. The gas segregation submodel determines the location of the gas vapor in the reservoir (whether it is in the gas-cap or in the oil zone) and will influence the amount of gas that is produced. The permeability equation regulates the flow of the gas and oil through the reservoir media and will also affect the amount of gas produced.

HAWKINS (WOODBINE) FIELD

The input data used for the Hawkins field simulations (Table 2) are the same as for the previous study (Mayer et al. 1980, p. 45). These values are based on information contained in the papers by King et al. (1976), Bell et al. (1951), and Wendlandt et al. (1946). The primary difference between this and the previous work is that the gas segregation model was modified in an attempt to better simulate a reservoir with an existing gas-cap on discovery. The original segregation model is as follows (USGS 1976): 


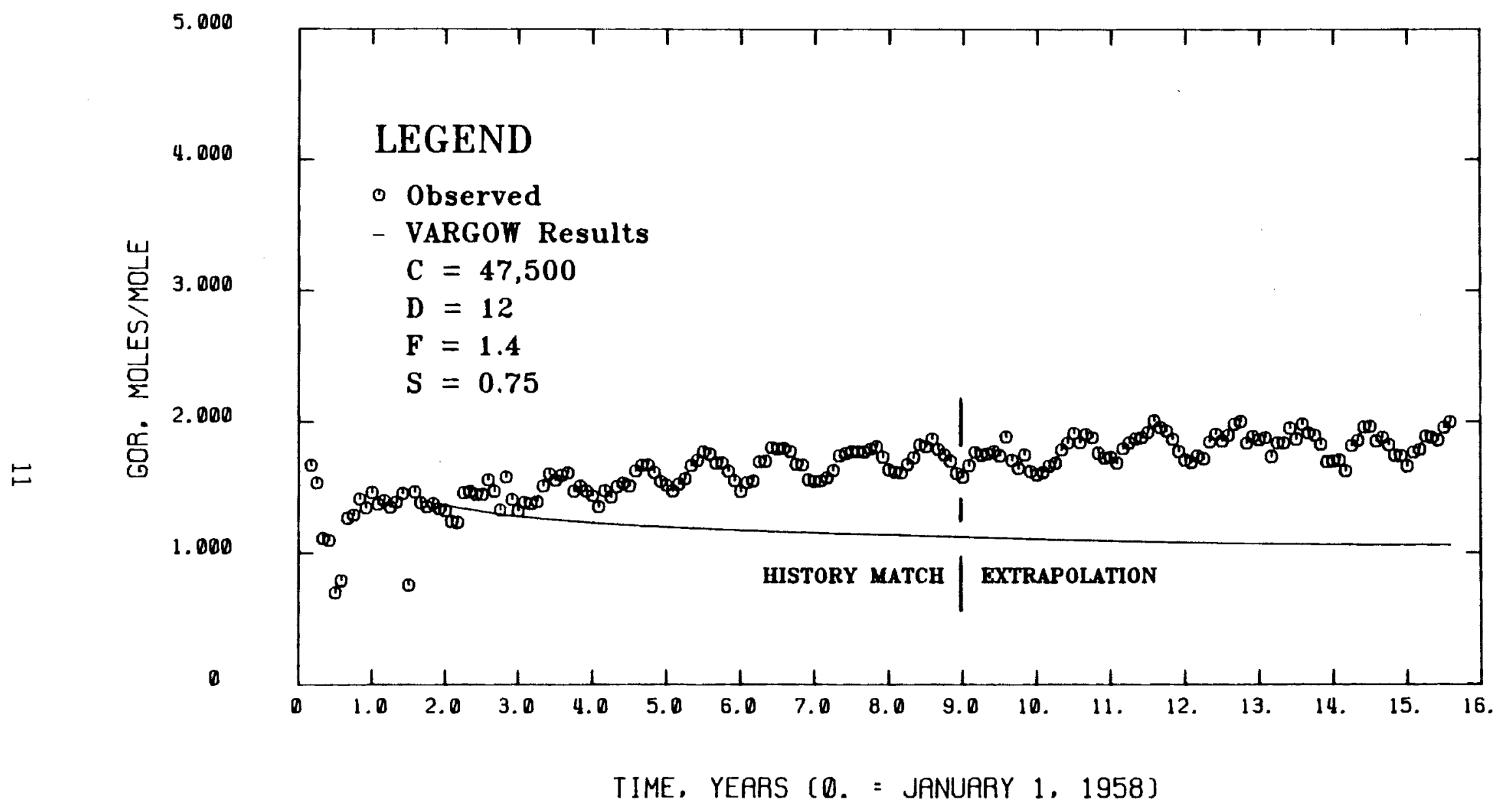

FIGURE 4. Empire Abo Pool Predicted Versus Actual GORS 
TABLE 2. Hawkins Field Input Data

\begin{tabular}{cll} 
Parameter & \multicolumn{1}{c}{ Value } \\
\cline { 1 - 1 }$A$ & est. $(a)$ \\
$B$ & est. \\
$C$ & $3.556 \cdot 10^{5}$ \\
$D$ & est. \\
$F$ & est. \\
$G$ & 1.016 \\
$N_{G C}^{O}$ & $4.081 \cdot 10^{9}$ \\
$N_{L}^{O}$ & $8.764 \cdot 10^{9}$ \\
$P^{0}$ & 1985 \\
$r_{O I L}^{O}$ & NA $(b)$ \\
$S$ & est. \\
$T^{0}$ & 345 \\
$V_{L}^{O}$ & $3.122 \cdot 10^{10}$ \\
$V_{r}$ & 1.223 \\
$\Delta_{O I L}$ & NA \\
MODEL & NA
\end{tabular}

(a) These values estimated statistically

(b) Not applicable

$$
N_{G C} / N_{F G}=S_{E} /\left(1-S_{E}\right)
$$

where

$$
S_{E}=S e^{-D / \theta}
$$


It is apparent that when time, $\theta$ is equal to zero this model forces the amount of gas-cap gas to be zero. Since this prevents the accurate simulation of reservoirs with a gas-cap on discovery the segregation model was modified as follows:

$$
\text { let } \begin{aligned}
S_{E} & =S_{1} e^{-D / \theta_{+}}+S_{2} e^{-\Theta / D} \\
\text { where } \quad S_{1} & =S, S_{2}=1 \text { if } N_{G C}^{0}>0 \\
S_{1} & =S, S_{2}=0 \text { if } N_{G C}^{0}=0
\end{aligned}
$$

This modification results in all of the nondissolved gas being placed in the gas-cap initially for all reservoirs that have a gas-cap on discovery. If, on the other hand, the reservoir has no gas-cap on discovery the original segregation model is used.

The results of the parameter estimation for the Hawkins Field reservoir, using the modified segregation model, show that $\vec{P}$ and $\vec{G}$ cannot be minimized with the same set of parameters. The pressure discrepancy measure, $\bar{P}$ is minimized for the following set of parameters.

$$
\begin{aligned}
A & =-1 \\
B & =6.25 \\
10 \leq D & \leq 14 \\
F & =5.25 \\
S & =\frac{122-6.19 D}{150.32}
\end{aligned}
$$

For the set of parameters with $D=10$ and $S=0.4$ the value of $\bar{P}$ is 121.98 psi. The pressure predictions using this set of parameters are shown in Figure 5. It is apparent that the predicted pressures are reasonably close to the observed values during the history match period although the curvature is not correct. In the extrapolation region the results deviate rapidly. 


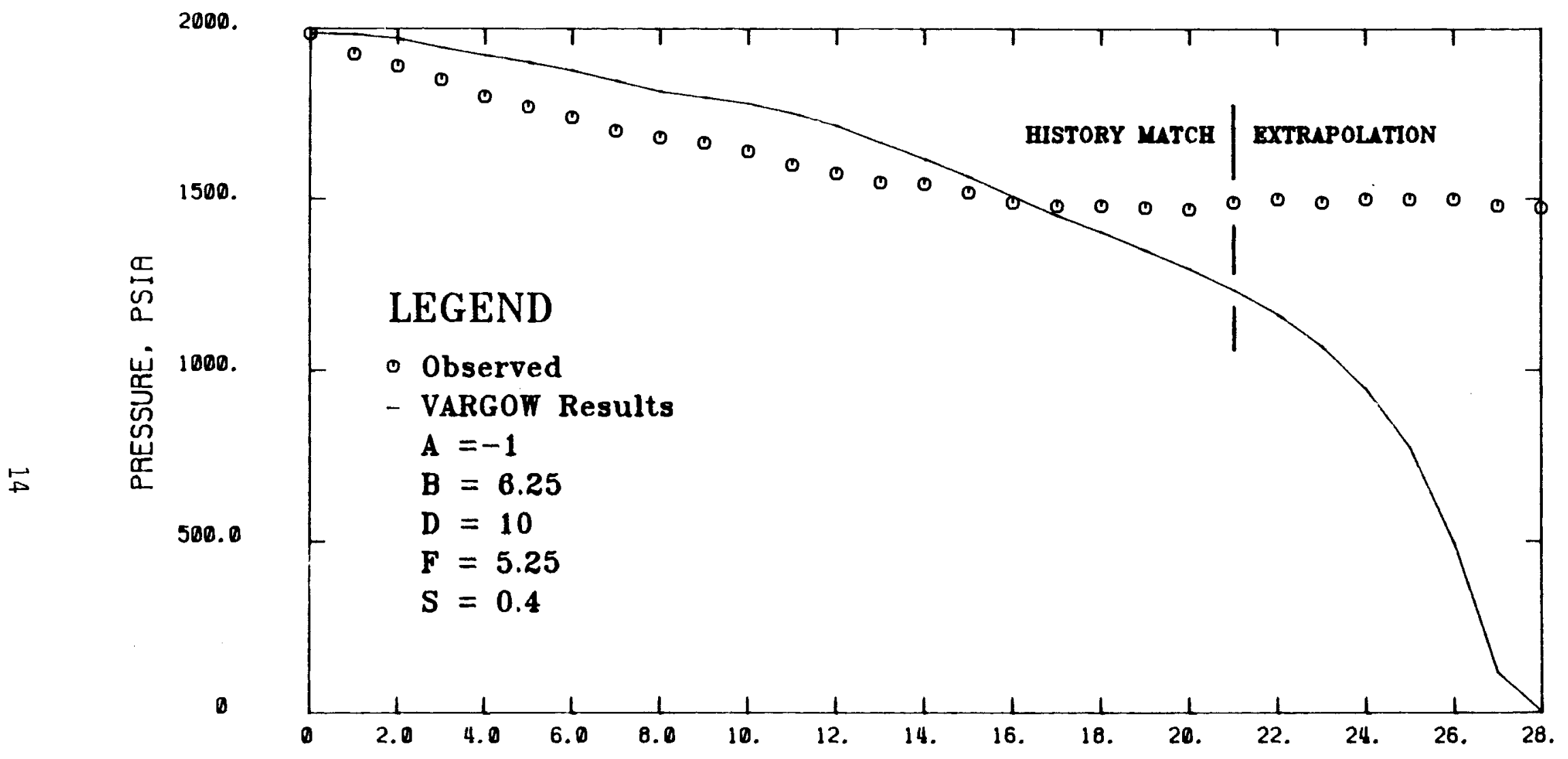

TIME. YEARS (0. = JAN. 1, 1941)

FIGURE 5. Hawkins Field Predicted Versus Actual Pressures 
The following set of parameters resulted in the minimum value for $\vec{G}$ :

$$
\begin{aligned}
& A=-2.15 \\
& B=6 \\
& D=21.4 \\
& F=4.8 \\
& S=0.58
\end{aligned}
$$

For this combination the value of $\vec{G}$ is 0.083 . The predicted GORs, using this set of values, are shown in Figure 6 and match the observed values quite well. The agreement is very good (as indicated by the very low value of $\bar{G}$ ) throughout the history match region. In the extrapolation region the GORs are underpredicted starting about three years into the extrapolation.

\section{GAS-CAP DRIVE RESERVOIR}

This reservoir had a gas-cap on discovery and has been simulated in essentially the same manner as Hawkins Field (modified gas segregation model used). The input data used for the simulations are included in Table 3 and are based on information obtained from the report by Kirby et al. (1957) and Stone et al. (1961).

The parameter estimation indicates that $\bar{P}$ will be minimized for the following set of parameters:

$$
\begin{aligned}
& D=0 \\
& S=0.4
\end{aligned}
$$

and will have a value of 36.5 psi. $\bar{G}$, on the other hand, will be minimized when

$$
\begin{aligned}
& D=33 \\
& S=0.3
\end{aligned}
$$

and will have a value of 0.2633 .

The results when $\bar{P}$ is minimized are shown in Figure 7 . The predicted pressures are in close agreement with the observed pressures throughout the history match and the extrapolation portion of the simulation. The extrapolated values appear to be underpredicting, however. The predicted GORs, Figure 8, match quite well during the first half of the history match and then start to overpredict. The trend is continued into the extrapolation region. 


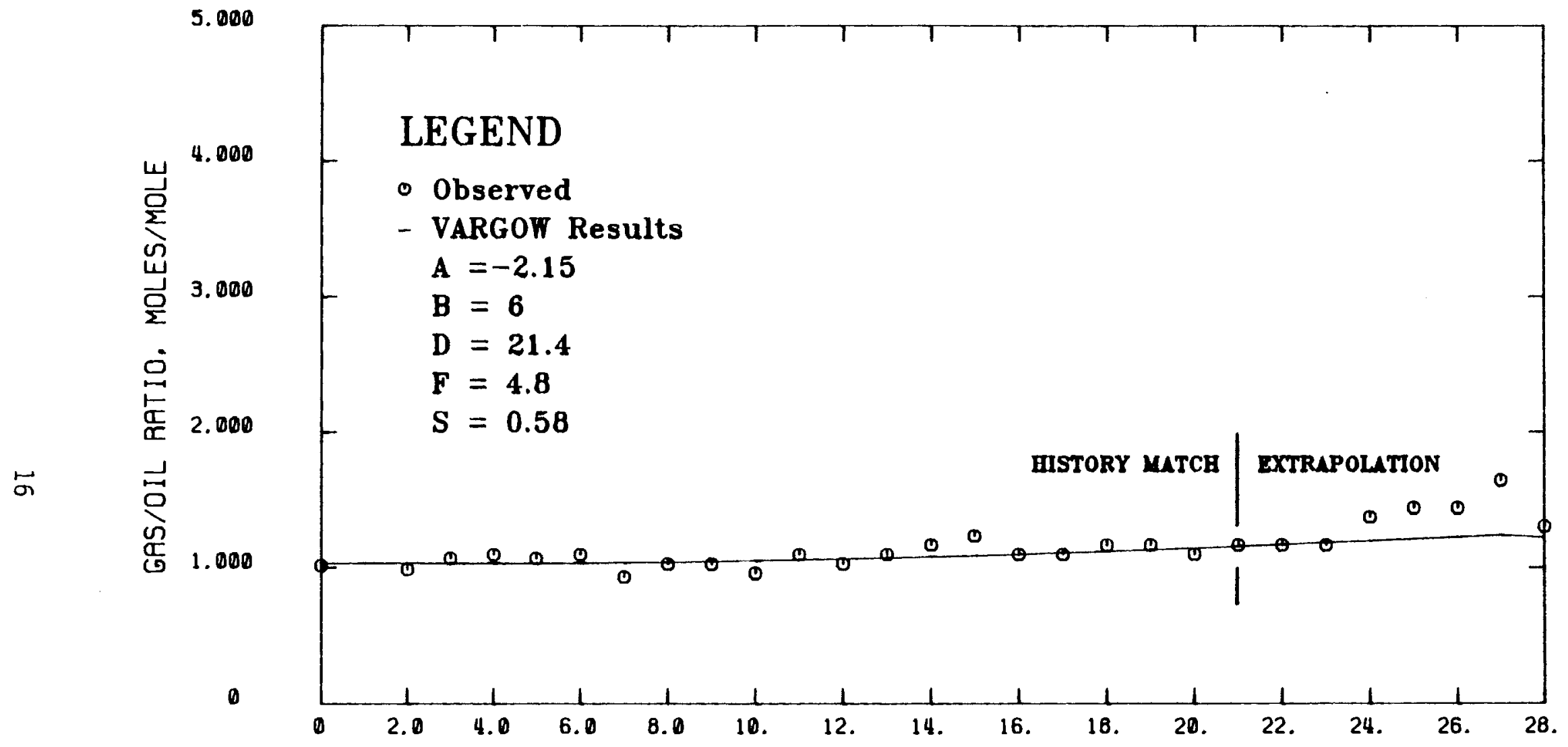

TIME, YEARS (0. = JAN. 1, 1941)

FIGURE 6. Hawkins Field Predicted Versus Actual GORs 


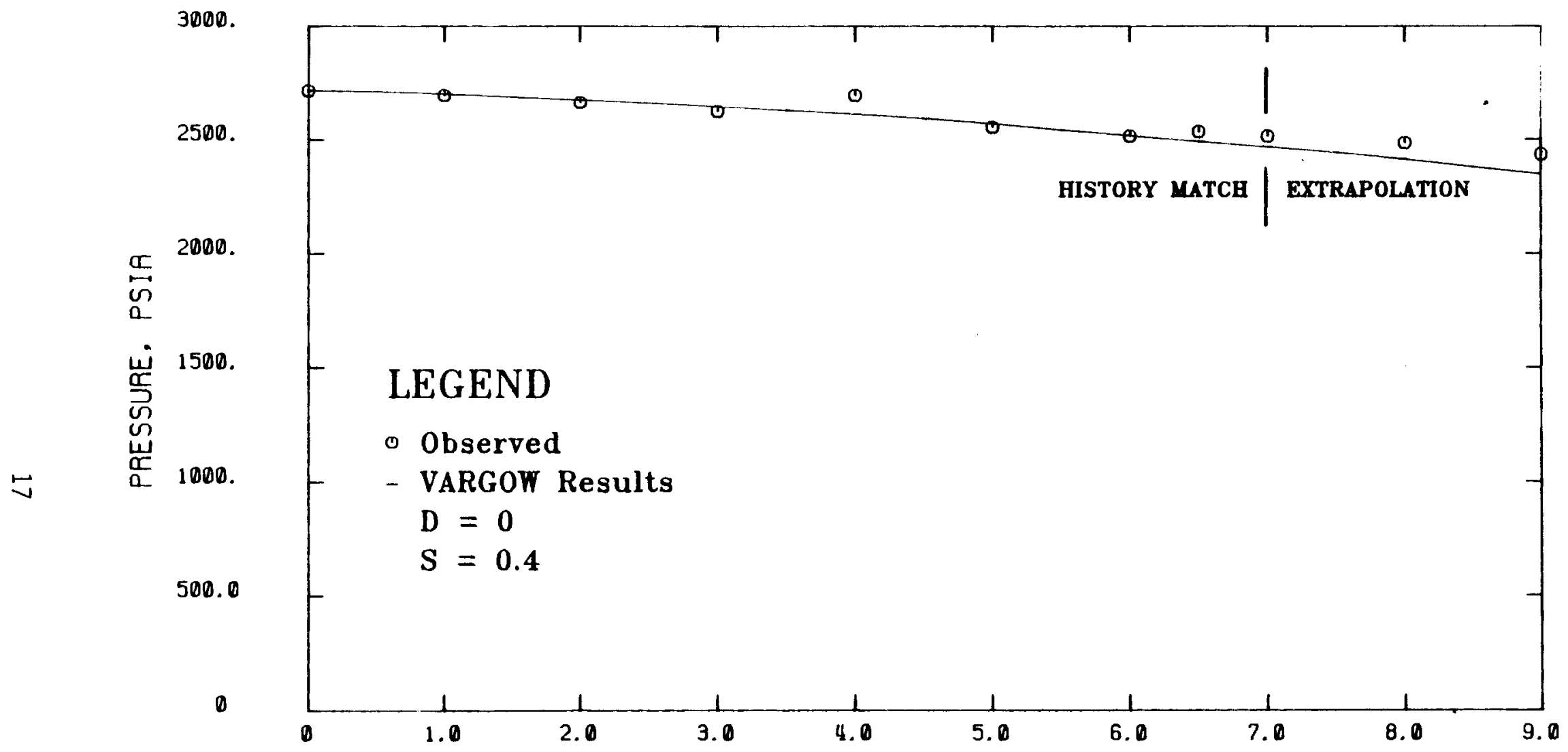

TIME, YERRS

FIGURE 7. Gas-Cap Reservoir Predicted Versus Actual Pressures 
TABLE 3. Gas-Cap Drive Reservoir Input Data

\begin{tabular}{cll} 
Parameter & \multicolumn{1}{c}{ Value } \\
\cline { 1 - 1 }$A$ & & -1.481 \\
$B$ & & 8.011 \\
$C$ & & 0 \\
$D$ & & est. $(\mathrm{a})$ \\
$F$ & & $0($ since $C=0)$ \\
$G$ & & 0.9803 \\
$N_{\text {GC }}^{0}$ & & $1.98 \cdot 10^{8}$ \\
$N_{L}^{0}$ & & $4.202 \cdot 10^{8}$ \\
$P^{0}$ & 2715 \\
$r_{\text {OIL }}^{O}$ & NA \\
$S^{(b)}$ & est. \\
$T^{0}$ & 356 \\
$V_{L}^{0}$ & $9.142 \cdot 10^{8}$ \\
$V_{r}$ & 1.355 \\
$\Delta_{O I L}$ & $N A$ \\
MODEL & $N A$ \\
&
\end{tabular}

(a) These values estimated statistically (b) Not applicable 


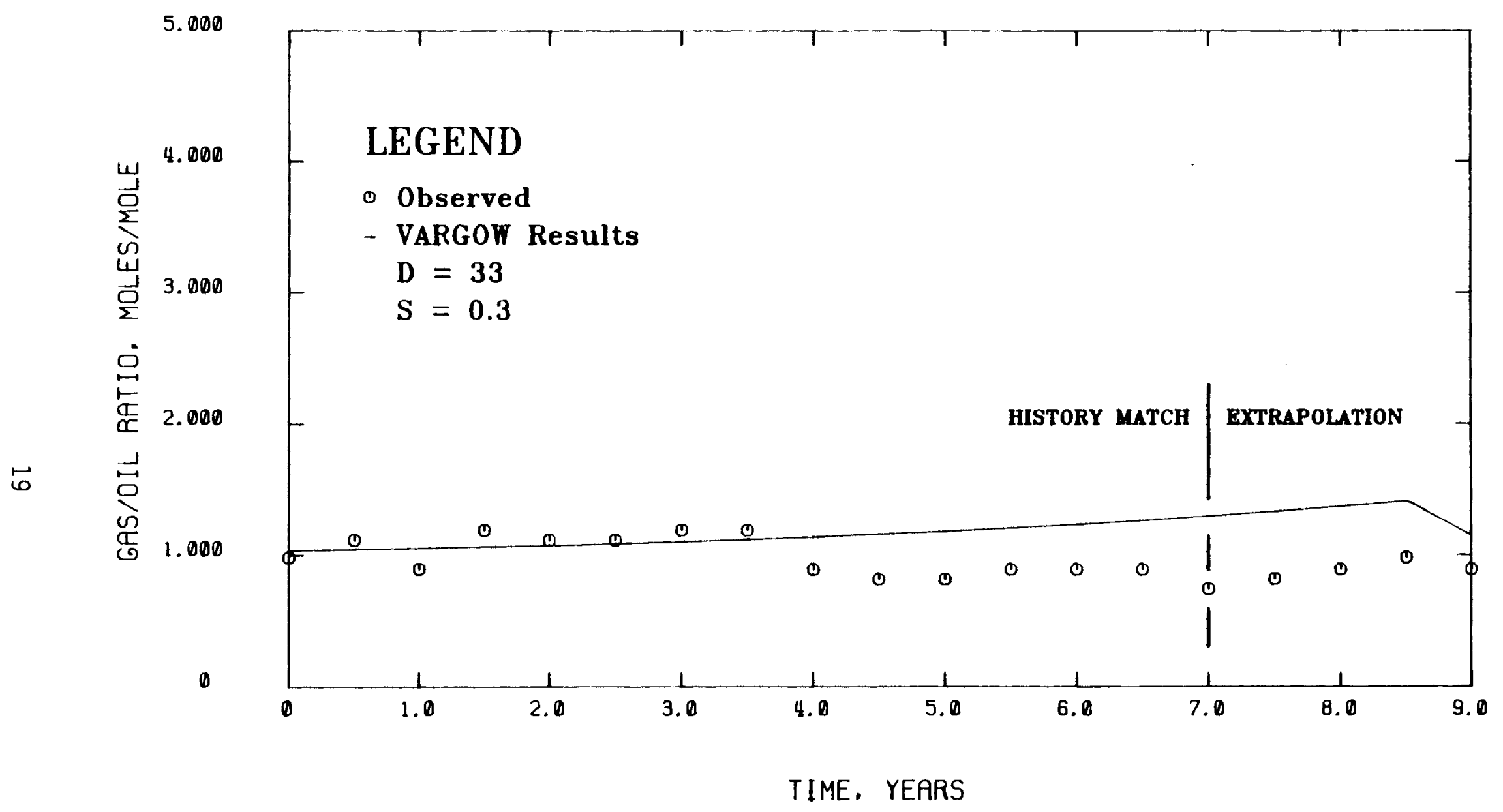

FIGURE 8. Gas-Cap Reservoir Predicted Versus Actual GORs 


\section{REFERENCES}

Annual Report. 1958-1978. New Mexico $0 i 1$ and Gas Engineering Committee. Vol. 1, Southeast New Mexico and Vol. II, Northwest New Mexico.

Be11, J. A. and J. M. Shepherd. 1951. "Pressure Behavior in the Woodbine Sand." Petroleum Transactions, AIME. 192:19-28.

Christianson, S. H. 1977. "Performance and Unitization of the Empire Abo Pool." Paper presented at the 1977 Permian Basin 0il and Gas Recovery Conference of the Society of Petroleum Engineers of AIME, March 10-11, 1977, Midland, Texas.

Killough, J. E. and H. P. Foster, Jr. 1979. "Reservoir Simulation of the Empire Abo: The Use of Pseudos in a Multilayered System." Society of Petroleum Engineers Journal. pp. 279-288.

King, R. L. and W. J. Lee. 1976. "An Engineering Study of the Hawkins (Woodbine) Field." J. of Petroleum Technology.

Kirby, J. E., Jr., H. E. Stamm III, and L. B. Schnitz. 1957. "Calculation of the Depletion History and Future Performance of a Gas-Cap-Drive Reservoir." Petroleum Transactions, AIME. 210:218-226.

Mayer, D. W., E. M. Arnold, W. M. Bowen and P. J. Gutknecht. 1980. Validation Status of the VARGOW 0il Reservoir Model. PNL-3478, Pacific Northwest Laboratory, Richland, Washington.

Stone, H. L. and A. 0. Gardner, Jr. 1961. "Analys is of Gas-Cap or DissolvedGas Orive Reservoirs." Paper presented at the 35th Annual Fall Meeting of Society of Petroleum Engineers, October 2-5, 1961, Denver, Colorado.

U.S. Geological Survey, Systems Analys is and Development Section. 1976. A Basic Reservoir Per Se Mathematical Model for Determining Ultimate Recovery Functions for a Variable Withdrawal Rate of a Gas-0il-water (VAR/GOW) System. SAD Section Report No. 77-10, U.S. Geological Survey, Conservation Division, Lakewood, Colorado.

Wendlandt, E. A., T. H. Shelby, Jr., and J. S. Bell. 1946. "Hawkins Field, Wood County, Texas." Bulletin of the American Association of Petroleum Geologists. $30(11): 1830-1856$. 


\section{DISTRIBUTION}

No. of

Copies

\section{OFFSITE}

A. A. Churm

DOE Patent Division

9800 S. Cass Avenue

Argonne, IL 60439

B. Walker

U.S. Department of the Interior Geological Survey

EGS-Mail Stop 620

Reston, VA 22092

27 DOE Technical Information Center

H. Tomlinson

U.S. Department of the Interior Geological Survey

EGS-Mail Stop 620

Reston, VA 22092

J. Gregory

U.S. Department of the Interior Geological Survey

EGS-Mail Stop 620

Reston, VA 22092

D. Kash

U.S. Department of the Interior Geological Survey

EGS-Mail Stop 620

Reston, VA 22092

Dr. J. Lohrenz

U.S. Department of the Interior Geological Survey

Conservation Division

Mail Stop 608

Box 25046, Denver Federal Center

Denver, CO 80225
No. of

Copies

E. Monash

U.S. Department of the Interior Geological Survey

Conservation Division

Mail Stop 608

Box 25046, Denver Federal Center

Denver, CO 80225

H. Oden

U.S. Department of the Interior

Geological Survey

EGS-Mail Stop 620

Reston, VA 22092

ONSITE

DOE Richland Operations Office

H. E. Ransom

16 Pacific Northwest Laboratory

E. M. Arnold

W. M. Bowen

S. M. Brown

D. B. Cear lock

D. W. Mayer (5)

Publishing Coordination (Be)(2)

Technical Information (5) 